\title{
BEDEUTUNGEN UND BILDER DER GEBÄRMUTTER IN DER HEBRÄISCHEN BIBEL
}

Pieter van der Zwan

Postdoktoraler wissenschaftlicher Mitarbeiter an der Universität Pretoria

Fakultät Theologie

Pretoria, 0002

Südafrika

E-mail: dr.pvdz@gmail.com ${ }^{1}$

(Received 12/01/2015; Accepted 05/06/2015)

\begin{abstract}
Die Gebärmutter kann in der Hebräischen Bibel durch vier verschiedene Wörter

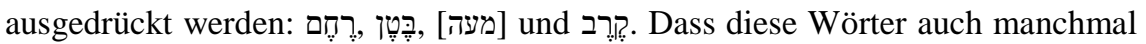
metaphorisch oder mit anderen Bedeutungen gebraucht werden, zeigt, dass sie auch diverse emotionelle Verbindungen haben. Darüber hinaus wird der Mutterschoß in mehreren Kontexten aus verschiedenen Perspektiven betrachtet, wobei er nirgendwo als Erfahrung (einer Frau) beschrieben wird. Stattdessen wird als Erinnerung der daraus Geborenen über den Mutterschoß reflektiert. So wird ein Netzwerk von - manchmal eher unbewussten - Assoziationen geschaffen, das die Spannbreite des Begriffs und seine möglichen körperlichen, psychologischen, sozialen oder transzendentalen Konnotationen erweitert und bereichert.
\end{abstract}

\section{EINLEITUNG}

Obwohl während der letzten Jahrzehnte über den Körper, die Geburt und Gott als Mutterfigur geschrieben worden ist, fehlt nach Kenntnis des Autors bisher eine eingehende Untersuchung der diversen Bedeutungen oder auch Fantasien über die Gebärmutter in der Hebräischen Bibel auf körperlicher, psychologischer, sozialer und transzendentaler Ebene.

Der vorliegende Beitrag untersucht deshalb die verschiedenen Rollen, Bedeutungen und Themen, die die Begriffe רֶּם (Mutterleib) in verschiedenen

1 Bedanken möchte ich mich beim DAAD für seine finanzielle Unterstützung und bei Prof. Dr. Maria Häusl an der Technischen Universität Dresden, die meine begeisternde Begleiterin bei diesem Forschungsaufenthalt war. 
Kontexten in der Hebräischen Bibel haben.

Zuerst wird ein Überblick des Körpers in der Hebräischen Bibel gegeben. Danach wird nach der Bedeutungsspannweite der Körperteile gefragt. Drittens werden die einschlägigen hebräischen Worte untersucht und viertens verschiedene Bedeutungsebenen der Gebärmutter betrachtet.

Bezüglich der verwendeten Methodologie und ihrer Darstellung in diesem Artikel sind folgende Punkte von Bedeutung:

1. Alle deutschen Bibelzitate sind aus der Einheitsübersetzung.

2. „Mutterschoß“, „Mutterleib“ und „Gebärmutter“ werden synonym verwendet.

3. Hebräische Grundformen stehen - ohne Kontext - stellvertretend für alle Ableitungen.

4. Obwohl es um Mutterschoßbilder geht, beschränkt dieser Beitrag sich nur auf die ausdrücklich genannten vier hebräischen Worte (also nicht z.B. Ps 90). Keine Rückschlüsse werden über mögliche Mutterschoßbedeutungen ohne diese Worte aus „indirekten“ Erscheinungen gezogen, wie Höhlen (z.B. das Meer, ein Haus, der Mund), Sitz, Thron oder Tod. Körperliche Funktionen wie Empfängnis, Schwangerschaft, Wehenschmerzen oder Geburt als Spiegelungen des Mutterschoßes werden ebenfalls nicht berücksichtigt. Das Umgekehrte ist aber der Fall: psychologische Deutungsmöglichkeiten werden aus Mutterschoßbildern erschlossen.

\section{KÖRPER UND KÖRPERTEILE IN DER HEBRÄISCHEN BIBEL}

Die feministische Bewegung hat dem Körper schon in den Sechzigerjahren Aufmerksamkeit geschenkt; seit den Neunzigerjahren werden Ausdrücke des Körpers in steigendem Maße auch in den Geisteswissenschaften untersucht (Gliserman 1996:3).

Unter ungefähr 250 Bezeichnungen für Körperteile in der Hebräischen Bibel sind die zwei äußerlich sichtbaren Körperteile, die am häufigsten erwähnt werden, das Gesicht und die Hand, während als die zwei inneren Organe לְִָָם (Herz) und (Mutterschoß), beides Hohlmuskeln, am häufigsten genannt werden (Schroer \& 
Staubli 2005:58 $)^{2}$. Wörter für äußerlich sichtbare Körperteile zeigen, wie der Körper von außen durch den Anderen wahrgenommen wird, Wörter für innere Organe verdeutlichen, wie der Körper sich selbst erfährt, obwohl das bei der Gebärmutter eher selten den Fall ist. Wolff ([1973] 2002:21-123) hat in seiner biblischen Anthropologie einen ganzen Abschnitt über den Körper in der Hebräischen Bibel geschrieben, aber die wichtigen Begriffe, רֶֶֶ (Mutterleib), vielleicht wegen eines patriarchalischen Vorurteils, übersehen (Schroer 1995b:170), ${ }^{3}$, obwohl er [מעה] als das auch die inneren Geschlechtsorgane einschließende Wort gesehen hat (Wolff 2002:102). Dies gilt auch für das Buch von Janowski über die Anthropologie der Psalmen (Grohmann 2007:402). Diese Lücke haben Schroer und Staubli (2005:57-66), die nur einige Beispiele dieser Begriffe betrachten, gefüllt, aber sie haben sie nicht weiter mit anderen Körperteilen oder mit psychologischen Einsichten verbunden.

\section{KÖRPERSYMBOLIK IN DER HEBRÄISCHEN BIBEL}

Wenn die Bezeichnungen für Körperteile in der Hebräischen Bibel bildsprachlich gebraucht werden, können sie metonymisch sein: Ihre Bildsprachlichkeit beziehen sie nicht von ihrer Form, sondern von ihren Funktionen (Keel 1984 passim; Wagner 2010:85ff.; Schroer \& Staubli 2005:21). Wolff (2002:23) bezeichnet dies als das „synthetische Denken“, bei dem die genannten Organe mit ihren Fähigkeiten und Tätigkeiten gleichbedeutend sind. Statt als Konkreta können sie damit auch als Abstrakta, statt als Nomina können sie auch als Verben, statt als Objekte können sie auch als Subjekte funktionieren.

In der Bildkommunikation geht es üblicherweise nicht (nur) um eine darstellende Abbildung (repräsentativ) oder (nur) um einen emotionalen Ausdruck (expressiv), sondern besonders um explizit performative bzw. deklarative Sachlagen. Andererseits handelt es sich bei Worten im Gebrauch meistens nicht um solche Deklarationen, sondern um repräsentative Darstellungen von deklarativen „Anwendungsfällen bzw.

2 Wahrscheinlich wird רֶּ als äußeres Organ angesehen. Warum ist aber nicht klar.

3 Kiesow (2003:35) nennt, dass er „Mutterleib“ als „Unterleib des Mannes“ nur einmal auf S. 102 seines 1984erschienenen Buches erwähnt. 
um die Darstellung oder um den Vollzug von anderen Sprechhandlungen (kommissive, expressive, direktive)“(Wagner 2010:97-98).

Es wird in diesem Artikel keine Begriffserklärung des Mutterschoßes gegeben, weil es nur um seine kontextbedingten Bedeutungen geht. Diese Bedeutungen können vital (biologisch), personal (psychologisch), sozial (kulturell) und transzendental (religiös) sein (Krieg 1983:9). Wie Strack (2014:100) es treffend formuliert: Jeder Körperteil weist über sich hinaus und umgekehrt hat jeder abstrakte Begriff eine Körperkonnotation.

Leider können die Kontexte ohne weitere Vergleiche nur schwer genauer interpretiert werden. Viele Umstände können sie beeinflussen (Häusl 2010:137). Obwohl die heutigen Leser durch mehrere Jahrhunderte von dem „ursprünglichen“ Hintergrund getrennt sind, steht doch fest, dass der Körper immer ein materieller und biologischer Organismus bleibt (Beer 1993:33,34), dass der Körper und seine Teile immer auch hierarchische Verhältnisse in der Gesellschaft (und deshalb Zugehörigkeit und Identität) symbolisieren (Beer 2002:36), und dass es vielleicht darum so viel weitverbreitete Ähnlichkeit von Körpermetaphern gibt (Beer 2002:33).

\section{HEBRÄISCHE LEXEME FÜR „GEBÄRMUTTER” IN DER BIBEL UND IHRE VERTEILUNG}

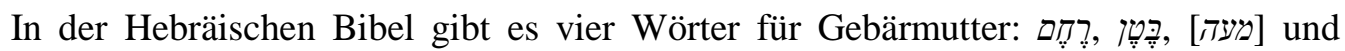
manchmal auch (wie vielleicht in Gen 25,22 und Ps 5,10 [Grohmann 2007:118]). Ersteres bedeutet immer „Mutterschoß“ oder im übertragenen Sinne „Geburt“, wie vielleicht in Ps 110,3, aber nicht in Ri 13,5, in dem es Mutterschoß bedeutet (wie Klein 1995:198n1 behauptet).

Das zweite Wort bedeutet in erster Linie „Bauch“ als Ursprung des Hungers, wie in Ijob 15,2; 20,23; 32,18.19 und 40,16 (Klein 1995:198) und in zweiter Linie „Mutterschoß“ (wie Ijob es meist benutzt), dann meistens den schwangeren Mutterschoß (Grohmann 2007:32), wie es auch ausdrücklich in Koh 11,5 steht: בִּרֶֶּ

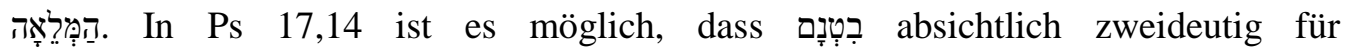
Schwangerschaft und Nahrungsaufnahme verwendet wird (Häusl 2002:217). 
In der Hebräischen Bibel kommen diese ersten zwei Wörter am häufigsten in Ijob vor: fünfmal bzw. 16mal. Oft besitzt ein Parallelismus, in dem diese beide Wörter zusammenschwingen, räumliche (buchstäbliche) und simultan zeitliche (übertragene) Bedeutungen (Grohmann 2006:77-78). Beide Wörter können eine zeitliche Bedeutung entweder seit der Empfängnis oder seit der Geburt haben (Grohmann 2007:323). Weil

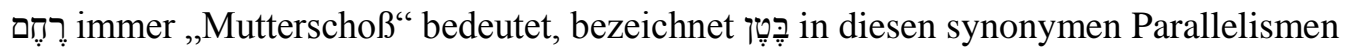
immer das Gleiche. Sie kommen achtmal (nicht sechsmal, wie Klein 1995:197-198n2 behauptet) in der Hebräischen Bibel so zusammen vor, dreimal in Ijob: 3,11; 10,18-19 und 31,15 und auch in Jes. 46,3; 49,15; Jer 1,5; Pss 22,11 und 58,4 (also, nicht „häufig“ in den Psalmen, wie Grohmann [2007:301] behauptet).

In Gen 25,23; Ps 71,6; Jes 49,1; Num 5,22 und Ez 3,3 werden Derivate (oder

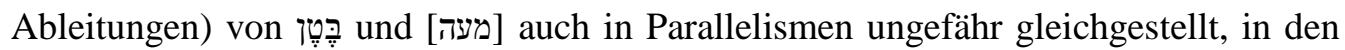
ersten drei geht es um den Mutterschoß, in den letzten zwei wahrscheinlich um den

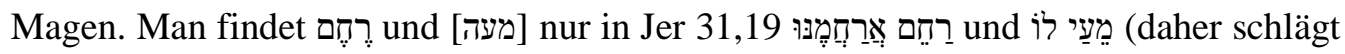

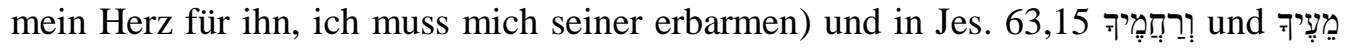
(dein großes Mitleid und dein Erbarmen) nebeneinander, aber da ist vom Mutterschoß nicht ausdrücklich die Rede, obwohl Trible (1993:63) es so in Jer 31,19 gerade wegen des zweiten Teils übersetzen möchte. Dieses Verständnis von Trible ist auch im Einklang mit der Klage Rahels in V. 14, die die bittere Enttäuschung ihres „Mutterschoßes“ beweint, den Gott in Gen 30,22 geöffnet hat (vgl. Trible 1993:57; $64)$.

Dass die drei Wörter oft synonym sind, wird dadurch nahegelegt, dass der

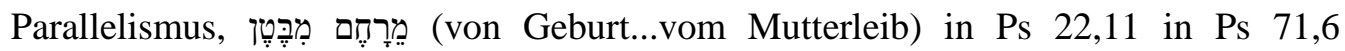

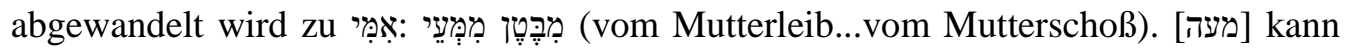
die Eingeweide, den Mutterschoß, einen inneren Gefühlsort oder den Bauch

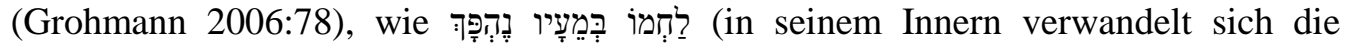

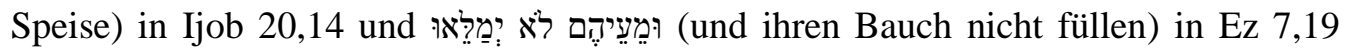
sowie den Ort der metaphorischen Verdauung in Ez 3,3, bedeuten. Aus dem

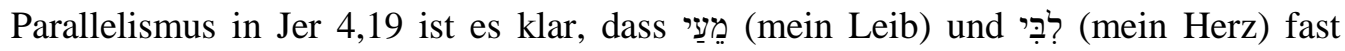

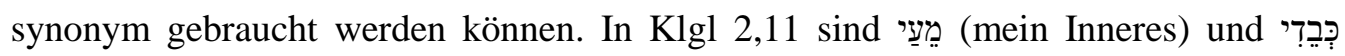


(meine Leber) ähnlich.

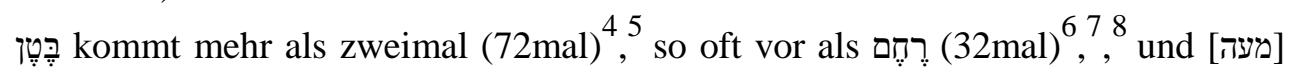
kommt (30mal) ${ }^{9}$ vor. Ersteres hat aber manchmal mehrere Bedeutungen, also nicht nur „Mutterschoß“, während das zweite Wort normalerweise den Frauenschoß insgesamt (Uterus / Vulva / Vagina) bezeichnet (Kronholm 1990:478). Nur in zwei Büchern der Tora, Lev und Jos, kommen nirgendwo der Mutterleib oder gar der Leib vor, obwohl über Geburt in Lev 12 gesprochen wird. Insgesamt wird wahrscheinlich mindestens $84 \mathrm{mal}$ ausdrücklich auf den Mutterschoß verwiesen, auch wenn er als Metonymie im Sinne von Schwangerschaft, Geburt (z.B. Jes 46,3) oder Kinder (z.B. Jes 13,18) funktioniert.

In Sprüche kommt das Wort

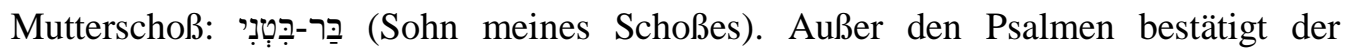

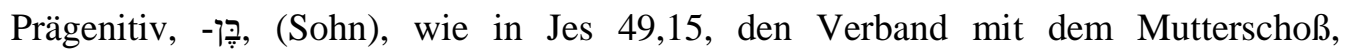
zumindest indirekt.

\section{DIE KONTEXTUELLEN BEDEUTUNGEN DIESER HEBRÄISCHEN WÖRTER}

Weil der Mutterschoß innerhalb des Körpers ist, hat er keine sichtbare Form, so kann seine Gestalt kein Thema sein. Er besitzt jedoch wie die anderen Körperteile auch eine

4 Baumann (2003:236) nennt רֶֶֶּ nur 34mal bei Frauen, immer als Mutterschoß, und 28mal bei Männern, d. h. insgesamt $62 \mathrm{mal}$.

5 d.h. 37mal in den Weisheits- (16mal in Ijob und 10mal in Ps), 19mal in den Tora- und 16 mal in den Prophetenbüchern, aber in nur 49mal wird nach Zeugung, unter denen wahrscheinlich drei auf einen Mann, verwiesen, also nur 46mal als „Mutterschoß“.

6 Wenn רַח in jeweils Jes 49,15 und Hab 3,2 mitgezählt werden, gibt das Wort 34mal in der Hebräischen Bibel.

7 Also nicht 30mal, wie Tryggve Kronholm, רֶֶֶ rohœm “ in Theologisches Wörterbuch zum Alten Testaments. Band 7. ((hg. G. Johannes Botterweck \& Helmer Ringgren. In Verbindung mit Georg W. Anderson et al. Stuttgart: W. Kohlhammer, 1990, 477behauptet.

8 d. h. 15 mal in den Tora-, neunmal in den Weisheits- (fünfmal in Ijob) und achtmal in den Prophetenbüchern)

9 d. h. neunmal in den Tora-, 11 mal in den Propheten- und zehnmal in den Weisheitsbüchern aber nur neunmal im Sinne von der Zeugung, unter deren fünfmal (Gen 15,4; 2. Chr 32,21; Jes 48,19) männlich, also nur viermal als „Mutterschoß“ 
körperliche, psychologische, soziale und transzendentale Bedeutung. Obwohl diese hier als Gesichtspunkte getrennt besprochen werden, stehen sie eigentlich immer miteinander in einer Beziehung.

\section{Körperliche Bedeutungen}

In der Sonderliteratur des Hohenliedes wirkt der aus männlicher Perspektive wahrgenommene weibliche Körper anregend. Er wird durch Übertreibungen und durch freie und offene Anspielungen idealisiert. Die Beschreibungen sind nicht unbedingt „objektiv” (Seidl 2000:146). Während der Mann in den Beschreibungsliedern eher äußerlich dargestellt wird, verweisen die Vergleiche und Metaphern bezüglich der Frau stärker auf ihre Wirkungen und innerliche Erfahrungen (Seidl 2000:150). Mit (mein Herz, eine Übersetzung, die Drewermann [1985:217]

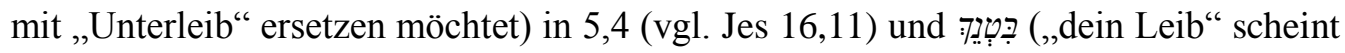
in der Einheitsübersetzung eher eine Vermeidung der Gebärmutter zu sein) in 7,3 geht es um den nicht sichtbaren, „inneren“ Frauenkörper, im ersten Fall um ihre körperlichen, psychosomatischen Erfahrungen, möglicherweise sogar um ihren Mutterschoß, und im zweiten Fall wahrscheinlich um ihren Mutterschoß als den vom Mann unbewusst wahrgenommenen Körperteil, der in seiner Bedeutung für sein möglicherweise dahinterstehendes Verlangen nach Kindern in Betracht gezogen wird (Van der Zwan 2014:854-858). In 5,14 verweist (ֵַָּיו (sein Leib) auf den ganzen äußerlichen, männlichen Körper bzw. Körperteil(e), d.h. sein(e) Geschlechtsorgan(e).

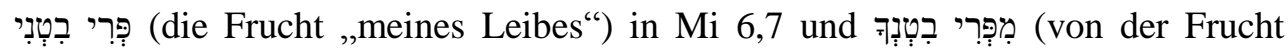
„deines Leibes“, d.h. aus deinem Geschlecht) in Ps 132,11 zeigen die Zeugung aus dem Inneren des männlichen Körpers. Hier geht es um den König und seine Dynastie, es hat deshalb eine eher politische Konnotation.

Als menschlicher oder tierischer ${ }^{10}$ „Mutterschoß“ kommt רֶ oft in Verbindung mit (ּุุ (das, was trennt, zum ersten Mal öffnet) vor, wie auch in Num 3,12; 8,16 und Ez 20,26. Es handelt sich in diesem Fall um ein heiliges (männliches) Erstlingsopfer.

Das Ganzheitsdenken und die Psychosomatik der Hebräischen Bibel wird

10 Alle Belege von רֶ in Ex: 13,2.12.15; 34.19 und auch Num 18,15. 
beispielhaft durch רֶֶ ausgedrückt (Grohmann 2007:130). Laut Stoebe (1976:762) konnte רַחָחמִִים (Mitleid) wahrscheinlich erst auf den Ort, die empfindliche Stelle, an der die intensive, tiefe Erfahrung stattfindet, dann auch auf das Gefühl, d.h. psychosomatisch auf die Eingeweide, inneren Organe oder Gedärme verweisen. Er glaubt deshalb, dass die Bedeutung des körperlichen Ortes, in Prov 12,10 negativ gemeint ist. Diese Vermutung wird auch durch die Parallelismen mit [מעה], das richtige hebräische Wort für Eingeweide, innere Organe, Gedärme oder Körper, wie etwa in Jes 63,15 , bestätigt.

\section{Psychologische Bedeutungen}

Verschiedene Gefühle werden mit verschiedenen Körperteilen verbunden, wobei das Herz am bekanntesten ist. In Jes 16,11 hat (mein Herz, oder anders als in der

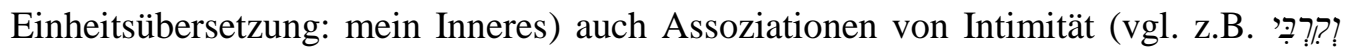

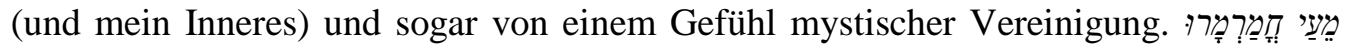

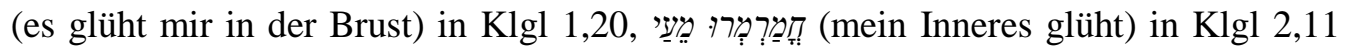

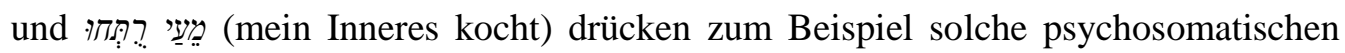

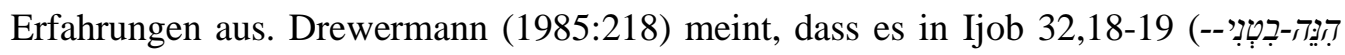

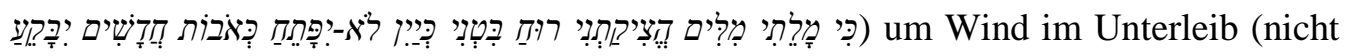
„Geist in meiner Brust") geht, d.h. um die unterdrückte Wut, die als Blähungen körperlich erfahren wird. Er fügt hinzu:

„Die Übersetzer hingegen scheuen sich, vom „Unterleib“ auch nur zu sprechen; stattdessen reden sie gegen das Lexikon lieber von der „Brust“, offenbar um die entsprechenden Empfindungen zu sublimieren. In der Psychoanalyse ist eine solche, Verlegung von unten nach oben“ als Abwehrvorgang bekannt [...].“

Starke Emotionen hängen mit dem Mutterschoß zusammen. Die zwei hebräischen Wörter, oder das andere am Anfang einer Reihe stehen kann.

Aus der Perspektive des Geborenen symbolisiert der Mutterschoß die Mutter, aber dass die Mutter selbst zu einem Organ als ihre Essenz reduziert wird, wie manche 
feministischen Auslegungen es verstehen, kann aber auch umgekehrt als die Erkennung der Wichtigkeit der Gebärmutter im Patriarchalismus gesehen werden (Gies 2009:183n84). Eine mögliche „Reduzierung“ (oder Verallgemeinerung?) des Frauseins auf die Gebärmutter (und deshalb Mutterschaft) ist eine Teilobjektbeziehung, die nicht nur kennzeichnend für das Kleinkind ist, sondern auch typisch für die Körperbeziehungen in der frühen Kultur, wie die aspektivischen Körperdarstellungen in den zwei- und dreidimensionalen Kunstwerken des Alten Orients beweisen. Hier gibt es nur Körpereinzelheiten, die nebeneinandergestellt worden sind, keinen ganzheitlichen Überblick über den Körper (Wagner 2010:80, passim).

Der Mutterschoß wird oft als synekdochisch und insbesondere als Pars pro Toto dargestellt (außer Ijob 3.10, vielleicht auch in 3.11, 10.18, 10.19, 24.20 und 31.15 [Klein 1995:198]), so wie es auch im Ugaritischen funktioniert und durch das abgeleitete Wort, רַַַ (Frau, wahrscheinlich abwertend gemeint), und seine Dualform,

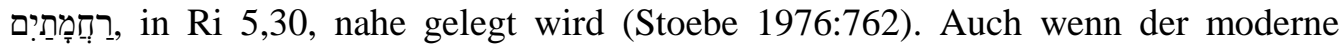
Philosoph, Peter Sloterdijk von „Uterodizee“ spricht, scheint das Organ aus patriarchaler Perspektive wichtiger als die Frau als Person zu sein (Strack 2014:19). Ob noch von einer Synekdoche gesprochen werden kann, wenn אִִ̣̣ (meine Mutter) als Mutterschoß gedeutet wird und damit das Gesamte einen Teil vertritt, wie Gies (2009:171) in Jer 20,17 versteht, ist fraglich. Wie bei Ijob bleibt die Mutter als Person in Jer 20,17 unbenannt. Aber es kann hier um eine Verallgemeinerung aus der Sicht des Fötus gehen: der Mutterschoß ist seine ganze Mutter, ja, seine ganze Welt. Er kennt nur den Mutterschoß, nichts Weiteres. Das enklitisches Personalpronomen zeigt, dass er den Mutterschoß als seinen eigenen Leib erfährt, er kennt nur einen Leib (Gies 2009:189). Das deutet also auf die enge Verbindung zwischen Mutter und Kind.

$\mathrm{Zu}$ dieser möglichen Reduktion der Frau, ist man aus patriarchaler Sicht nicht nur unausweichlich wegen der impliziten Unreinheit des Schoßes der Mutter (Ijob 14,1; 15,14 und 25,4) befleckt, sondern man leidet deswegen und man wird daher auch mit dem Grab verbunden (Ijob 3,11). Der schwangere Mutterleib wird, wie in Hos 13,1213, mit einem Gefängnis des Sünders verglichen, das er sich durch seine Sünden als 
ihn fest umschließende Tathülle geschaffen hat (vgl. Häusl 2005:9). Andererseits ist die unfruchtbare Frau wie eine Witwe (Ijob 24,21): Es scheint, als ob die Leere, „die der männliche [Körper] füllen muss" (Schmölzer 2005:10) als negativ interpretiert wird. Ohne ihre erfolgreiche Gebärmutter ist eine Frau nur bejammernswert (vgl. auch Häusl 2005:10). Es wirkt wie eine Zwickmühle. Auch Gott kann einen Mutterschoß haben, aus dem Verwüstung und der Tod kommen (38.8 und 38.29).

Das zeigt die Ambivalenz des Mutterarchetyps (Neumann 2004:52), wie sie alle Ursymbole immer haben (Strack 2014:37). So eine Urbasis im Leben wird leicht zu einer Projektionsfläche, auf der die Spaltung zwischen positiven oder negativen Gefühlen und Objektbeziehungen (Häusl 2010:151) ausgedrückt wird: das Leben oder der Tod. Die Abspaltung der Anima verursacht die Desintegration der Person. Für die Individuation ist die Integration der Archetypen der Anima (und des Animus) am schwersten. Nur durch Innigkeit mit dem anderen Geschlecht ist psychische Entwicklung möglich (Kassel 1987:230-231).

Der Mutterschoß, der zwölfmal genannt wird, ist der Ursprung des Leidens des Menschen. Wenn es Ijob schlecht geht, verflucht er in seinem Todeswunsch die Fruchtbarkeit seiner Mutter und den Mutterschoß, aus dem er geboren ist, (ähnlich wie in Jer 20,18; vide infra) und so implizit seine Mutter und Gott, die beide durch den Mutterschoß symbolisiert werden, aber sich auch hinter ihm verbergen. Die Verneinung (Gies 2009:170) der indirekten und verschobenen (gerade wegen der Tabuisierung in Ex 21,17 und Lev 20,9!) Verfluchung seiner Eltern ist darum nicht überzeugend. Der Mutterschoß als Ort der Erwählung und Berufung wird also auch manchmal der Ort der Verfluchung, v.a. im Buch Ijob, das Frauen fast ganz verschweigt (Maier \& Schroer 1998:197), obwohl es das Buch der Hebräischen Bibel ist, in dem am häufigsten ausdrücklich der Mutterschoß genannt wird.

Otto Rank ([1923] 1988:37) hat in den 20-er Jahren des Zwanzigsten Jahrhunderts nicht nur die Erfahrungen in der Gebärmutter als lebensprägend und als körperlich gespeichertes Gedächtnis nachgewiesen, sondern auch diese positive Urerinnerung, die man durch „Verfluchung“ als Abwehrmechanismus verdrängt, als lebenslange Sehnsucht und unterliegendes Heimweh interpretiert. Andererseits glaubte der 
ungarische Psychoanalytiker, Sándor Ferenczi (1924:27), dass die Sexualität eigentlich ein unbewusstes Verlangen in den Mutterschoß zurückzukehren ausdrückt. Obwohl er nicht von vielen Wissenschaftlern ernst genommen wurde, hat er alte Glaubensvorstellungen aufgegriffen: Nicht nur ist der Mensch Erde und soll zu Erde werden (Gen 3:19), sondern laut Ijob 1:21 kehrt man auch in den Bauch seiner Mutter zurück. Der Koran lehrt in Sure 2:156, dass der Mensch beim Sterben zu Allah zurückgeht, wie seine 끄 (Geist, Atem) in der Hebräischen Bibel zu Gott zurückkehrt (Koh 3:21; 12:7). Der Tod, Gott, die Erde und der Mutterschoß könnten deshalb zumindest im Unbewussten verbunden sein.

Das Buch Jeremia, beginnt mit einem Schwangerschaftsmotiv (in 1,5): Gott hat den Propheten schon vor seiner Formung im Mutterleib gekannt und ihn im Mutterschoß berufen, wie auch Simson als Nasiräer in Ri 13,5.7 und den Knecht JHWHs als Diener in Jes 49,1. Bei allen fünf vorgeburtlichen Berufungen in der Hebräischen Bibel (Ri 13,5.7; Jes 44,2.24; 46,3; 49,1; Jer 1,5), wird der Mutterschoß ausdrücklich genannt.

Aus einer psychoanalytischen Sicht kann man ahnen, dass im dichterischen „Antipsalm“ (Gies 2009:160), Jer 20,14-18, der Mutterschoß, in dem der Prophet in Jer 1,5 berufen wurde, auch verflucht sein mag. Der Geburtstag und der Mutterschoß verschmelzen in einer Verdichtung miteinander. Der eine wird (auch) metonymisch für den Anderen benutzt. Dabei wird die Berufung als „Grund von Leben“ (Gies 2009:170) in diesem Sinne ebenfalls verflucht. Durch die dreimalige Wiederholung des Mutterschoßes in Jer 20,17-18, der immer nur mit dem Wort, רֶֶ, benannt wird, sowie durch die Litotes wird der Mutterschoß hier hervorgehoben. Dass er sich nicht nur seinen eigenen Tod „im“ Mutterschoß (wie auch laut der Einheitsübersetzung,

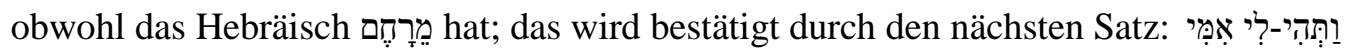
Sִ קִברִ ,So wäre meine Mutter mir zum Grab geworden“), sondern auch den seiner

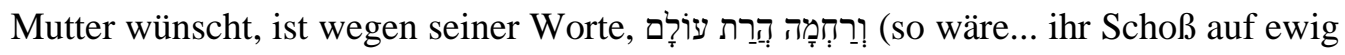
schwanger geblieben), klar: Er sollte im Mutterschoß sterben, aber in seiner Mutter bleiben, die dann auch mit ihm sterben sollte. Das ist natürlich nur möglich, wenn אִִ̣̣ (meine Mutter) nicht (nur) als Synekdoche für ihre Gebärmutter (Gies 2009:171) 
verstanden wird. Dieser Todeswunsch kann psychologisch auch als Neid auf die Fruchtbarkeit seiner Mutter verstanden worden (Schmölzer 2005:passim), weil der Tod - sein Leichnam als Penis - die furchtbare Erdmutter als Archetyp befruchtet und er dann auch an Befruchtung beteiligt würde, ohne Inzest (Neumann 2004:65,70). Andererseits kann sein Selbstmord im Dienst seiner Mutter als Großer Mutter und als Verschiebung der fressenden Erde, der er sein Leben opfern möchte, angesehen werden (Neumann 2004:68). Die Auseinandersetzung mit der Gebärmutter löst das übermächtige Unbewusste aus und stellt die Mutter als Böse vor (Neumann 2004:52). Wenn er im Mutterschoß geblieben und gestorben wäre, würde er die Nahrung des vorher nährenden Organs, der Uroboros, der sich selbst auffrisst (Neumann 2004:40).

Tatsächlich wird die Mutter verdinglicht (Gies 2009:174), weil nur eine Frau, nicht ein Mutterschoß, הָרֵת (schwanger) werden kann. Darum fragt er rhetorisch in

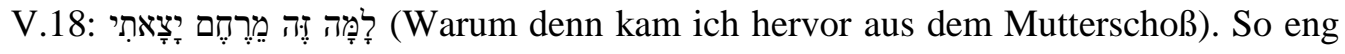
identifiziert er sich mit seiner Mutter. Hier kann gefragt werden, ob er unbewusst eine Angst vor der Trennung von seiner Mutter (wegen des Leides im Leben) hat, und deshalb eher in seiner Mutter bleiben will, auch wenn sie dann sein Opfer wird.

Diese negativen Gefühle bestehen auch, wenn der Mutterschoß als Ort des Aufstandes gegen Gott und unbewusst vielleicht auch gegen die Mutter in Jer 20,17 und Ijob 3,11 wird, obwohl Grohmann (2007:257) glaubt, dass Ijob sich einen Tod unmittelbar nach seiner Geburt (er war noch Zeuge der Mühsal) erwünscht, aber in 3,16 eine Fehl- oder Todgeburt (2007:246).

Die persönliche Geschichte und der Gottesstreit haben auch schon im Mutterleib Wurzeln bzw. ihren Ursprung: Laut Hos 12,4 gab es Geschwisterrivalität zwischen Jakob und seinem Zwillingsbruder bereits im Mutterschoß.

\section{Soziale Bedeutungen}

Der Begriff Mutterschoß beinhaltet auch Beziehungen zwischen Menschen. Wie die Mutter das Kind im Mutterschoß trägt, so trägt das Erbarmen, das Nicht-Vergessen (Jes 49,15 und Hab 3,2) die andere Person(en) in sich. (Darüber hinaus sind alle Erwähnungen des Mutterschoßes natürlich Beweise, dass die Gebärmutter auch nicht 
vergessen worden ist.) Diese Verbindung zwischen dem Mutterschoß und dem Erbarmen ist aber nur bedingt, weil sich erstens eine Mutter in Jes 49,15 hypothetisch trennen kann, und zweitens auch jemand ohne einen Mutterschoß erbarmend sein kann (Jüngling 1991:87). Im Deutschen fangen diese Worte oft mit „Mit-“ oder „Em-,, (d.h. „ein-“) an. In der modernen Psychologie stehen solche emotionellen Erfahrungen im Kontrast zum Narzissmus, es steht also das Ich-Denken gegen das Du- / Ihr- / WirDenken. Diese heftigen Gefühlsregungen werden mit Mutterliebe verglichen, obwohl auch ein Vater sie empfinden kann,

Grohmann (2007:120-121; 130) hat wahrscheinlich recht, dass der lautliche

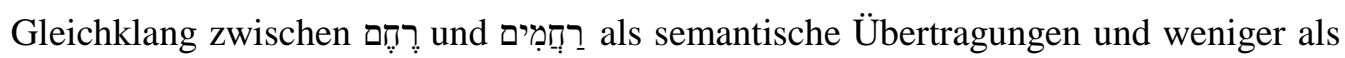
etymologische Entsprechungen betrachtet werden soll, weil es zwei semitische Wurzeln gibt, die im Akkadischen deutlich sind: râmu (lieben) und rêmu (sich erbarmen). Der Mutterschoß wird zwar als Sitz dieser Emotion angesehen. Diese Verbindung zwischen dem Mutterschoß und Erbarmen ist auch klar aus Ps 77,10: Wie Gott den Mutterschoß schließen kann (vide infra), kann auch gefragt werden, ob er

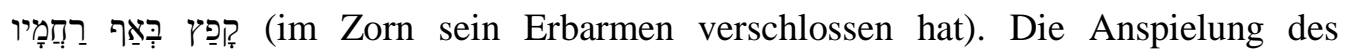
Erbarmens auf die Gebärmutter wird durch die möglicherweise parallele Fügung לִדר וָדָר (,,von Generation zu Generation“, d.h. für alle Zeiten) in Ps 77,9 verstärkt (Grohmann 2007:128). Weil alle vier anderen Vorkommen der Grundwurzel von in der Hebräischen Bibel immer Körperteile als Objekt haben, ist es wahrscheinlich, dass es in Ps 77,10 auch um einen Körperteil geht, der verschlossen wird. In Jes 63,15

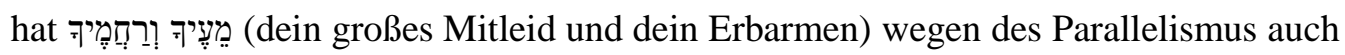
den ,physischen Beiklang von ,Inneres“ “ (Dahmen \& Simian-Yofre 1990:467). Grohmann (2007:124-125) sieht diese Verortung des Emotionalen (und der

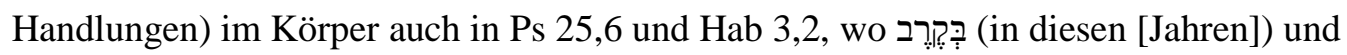
רַחֵם (Zorn), dessen Grundwurzel „erbeben“ heißt und von Grohmann an Geburtswehen und den Mutterschoß erinnert, wird in Hab 3,16 als eine Verbalform mit בִִִּ (mein Leib) verbunden. Das Abstrakte wird also im Körper konkretisiert.

Laut Ijob 31,15 sind alle Menschen dank ihres Ursprungs gleichberechtigt, alle 
wirtschaftlichen und gesellschaftlichen Unterschiede werden geglättet. Der Mutterschoß, der, wie der Tod ([die griechische] Weisheit Salomos 7,1-4), alle eint, bekommt eine ethische Bedeutung (vgl. Trible 1993:52). Trotzdem werden die Frevler und die Berufenen (vgl. auch [das griechische Buch] Jesus Sirach 1,14b) deutlich in ihrem Schicksal unterschieden, wie auch das Schicksal der Weltgeschichte in Gen 25,23 beweist: Zwei unterschiedliche Völker teilen den gleichen Mutterschoß.

Nicht nur das Wunder des Lebens und die Bestimmung, die Berufung und Vorsehung im Mutterschoß (in Ri 13,5; Jes 44,2; 49,1.5; Jer 1,5), sondern auch das Umgekehrte gilt: die Frevler und Lügner fangen schon im Mutterschoß mit ihrem „Lebensstil“ an. In Ps 58,4, ein Psalm, der viele Körperteile und Tiere nennt, so als ob das „Schicksal“ schon im Leib verkörpert wäre (Grohmann 2007:242-243; vgl. auch Jes 48,8). Umgekehrt sind die Frevler metaphorisch auch selbst schwanger mit Übel in

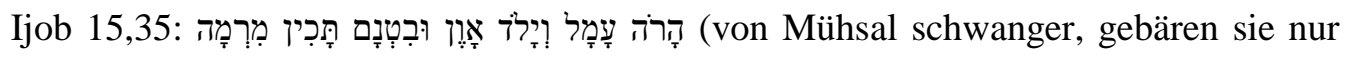
Unheil; nur Trug ist, was ihr Schoß hervorbringt), die Mühsal, die auch Ijob 3,10 und Jer 20,18 mit der Geburt verbinden: לִראוֹת עָמָל וָיָגוֹן (um nur [eher körperlich, behauptet Gies (2009:172)] Mühsal und Kummer zu erleben). Weil die Mühsal außerhalb des Mutterschoßes anfängt, wird der Mutterschoß eigentlich idealisiert. Deshalb bezieht diese „Mühsal“ sich hier nicht auf das Leiden der Mutter während der

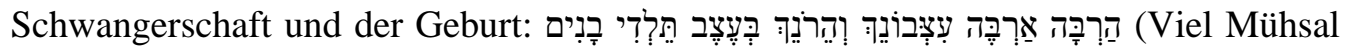
bereite ich dir, sooft du schwanger wirst, unter Schmerzen gebierst du Kinder) in Gen 3,16 .

Wie in einer körperlichen Schwangerschaft brauchen die Frevler zum Planen ihrer Übel Zeit und sie entwickeln sich auch im Verborgenen, im Geheimen. Dass der Mutterschoß beide romantisiert und als Bild der Entstehung des Übels benutzt wird, zeigen die Doppelwertigkeit von Gebärmutter, Geburt und Fruchtbarkeit (Grohmann 2007:122) und die psychologische Komplexität dieses Körperteils.

Grohmann (2007:33) hat über Ps 139,13-16 die Dialektik zwischen Gottes Sehen und der Verborgenheit und Geborgenheit in der Gebärmutter während „der längsten Nacht" (Sloterdijk 2000:381) hervorgehoben. In Ijob 3,10 bedeutet aber das Nicht-

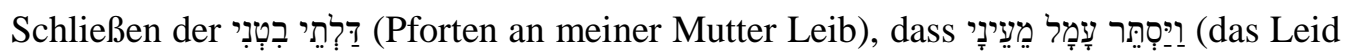


vor meinen Augen [wörtlich: von meinem Leib (im Plural)] [nicht] verborgen ) worden ist.

Der Mutterschoß schafft, wie הַָּרָע (die Rippe) in Gen 2:23, die auch Nebenräume z. B. in 1. Kön 7,3 bedeuten kann, auch architektonische Vorstellungen. Sowohl Freud (1929:128f und 1986:85 and 225) als auch Jung (1984:116) haben die symbolische Verbindung zwischen Gebäuden (insbesondere Häusern, aber vielleicht auch Städten wie Beten in Jos 19,25) und Körpern oder Körperteilen bemerkt. In Ps 71,6 geht es um das Geborgenheitsgefühl, wie es in einem solchen Kontext ausgedrückt wird. Die Beziehungen zu anderen Symbolen des Körperzentrums wie לִָרָ sind hierfür wichtig.

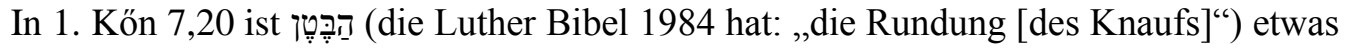

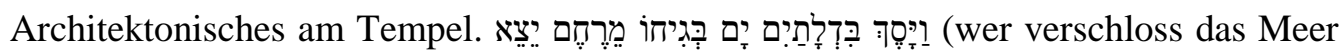
mit Tִּי לא

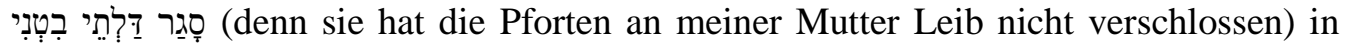
Ijob 3,10. Türen, Pforten oder Tore weisen auf den Muttermund. In beiden Fällen geht es um die Geburt, nicht um die Empfängnis wie es wahrscheinlich in Gen 30,22 der Fall ist, weil die Empfängnis, die Schwangerschaft, erst danach in V. 23 genannt wird (vide supra). In Jes 66,9 beziehen sich das Schließen und das Öffnen des Mutterschoßes aber auf die Geburt. Umgekehrt wird die Dreiteilung des Mutterschoßes als Vagina, Gebärmutter und Eierstöcke auch als Plan für die Tempel, d.h. heilige Orte, in verschiedenen antiken Kulturen gebraucht: der Eingang, das Heilige und das Allerheiligste (Strack 2014:41). Jost \& Seifert (1998:286) sehen den Tempel als Vagina und Gebärmutter Jerusalems (als fraulichen Körper), leider aber ohne weitere Erläuterung.

Dass Gott auch in sozialen Rollen auftritt, wird aus verschiedenen Berufsbildern, die für das Geschehen im Mutterleib verwendet werden, klar. Es werden beide Textil- und Textbilder - verwendet, um die Entwicklung מָּלִִִ (mein(es) Knäuel(s), des ungeformten, unfertigen Urzustands) - der aber schon von Gott (an)erkannt wird dichterisch zu beschreiben. Laut Ri 16, 13-14 und Prov 31, 13.19-25 ist das Weben eine weibliche Beschäftigung und Gott wird also hier als weiblich vorgestellt (vgl.

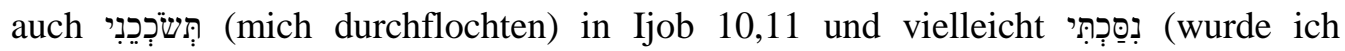


gebildet) in Prov 8,23). Ein anderes, wahrscheinlich frauliches Bild ist das der Käserin in Ijob 10,10 (vide supra).

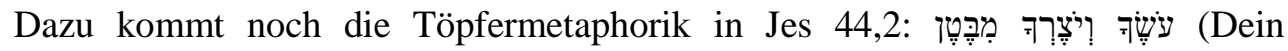

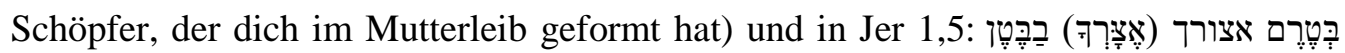
(noch ehe ich dich im Mutterleib formte [vgl. auch Ijob 10,9, wo Ton parallel mit dem Staub, eine Anspielung auf den Tod, gestellt wird]. Im Ps 139,16 (wie in Ps 74,17 die Zeit, in Ps 33,15 das Herz und in Ps 94,9 das Ohr) sind es die Tage des Menschen, die im Mutterschoß (wie aus Ton, רמָז, in Ijob 10,9) geformt werden. In Jer 1,5 ist wahrscheinlich sogar von Gottes Erkennen und Ausersehen (vơ טִּרִ (vor) dem Mutterschoß die Rede. Der Mutterschoß ist daher nicht der absolute Ursprung des Menschen. Die Mutter, weil sie nicht ausdrücklich genannt wird, wird auch nicht anerkannt. In Ijob 3,11 und 10,18 bleibt der Mutterschoß mehrdeutig (Bauer 1998:259), nur vom Eingang und Ausgang ist die Rede, über den „Aufenthalt“ im Mutterschoß wird nichts gesagt.

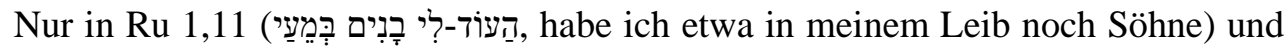
aus Prov 31,2 scheint es, als ob Frauen selbst in der Hebräischen Bibel über ihre Gebärmutter sprechen (vgl. auch das griechische Jdt 9,2). Auch wenn diese zwei Texte nicht von Männern über Frauen geschrieben worden sind, erfolgt an allen anderen Belegstellen die Zuschreibung von Bedeutungen immer aus männlicher Perspektive, nämlich die entweder eines Sohnes oder eines Befruchters des Mutterschoßes ist.

Die Ähnlichkeiten im monologischen Ijob 3 mit Jer 20 können wahrscheinlich entweder wegen seiner textuellen Abhängigkeit oder eines gemeinsamen textuellen Hintergrunds erklärt werden (Gies 2009:182-183). In V.10 wird die Mutter Ijobs („elliptisch“ [Grohmann 2007:301]) und in 19,17 wahrscheinlich seine Frau (Klein 1995:198f) als eigentliche „Besitzerinnen“ des Mutterschoßes, in den sie verschwinden, verschwiegen: Der Mutterschoß wird eine Synekdoche der Frau Ijobs, die er dann sozusagen besitzt (wie seine Frau hypothetisch auch von einem anderen Mann in 31,10 besessen oder als gesellschaftliche Opfer in Ijob 24 und 31,13.16 geholfen werden kann) und so als seinen eigenen Körperteil betrachtet. Weil בֶּ einfach „Körper“ im Allgemeinen bedeuten kann, muss man hier nicht unbedingt eine 
dichterische Zuordnung des Mutterschoßes dem Mann (z.B. in Ps 132,11) annehmen, obwohl „Türen“ oft mit dem Mutterschoß verbunden werden, die Gott öffnen (z.B. Gen 29,31; 30,22) oder schließen (z.B. Gen 20,18; 1 Sam 1,5.6; Prov 30,16) kann, beides Gotteserfahrungen (Drewermann 1985:184). Beim Schließen oder Öffnen könnte es eher um die Empfängnis gehen und nicht um die Geburt, wie in Ijob 3,10 (vide infra).

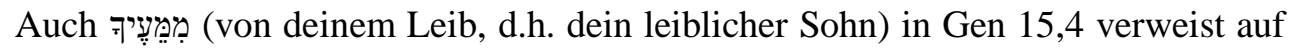
den Körper eines Mannes und in Jes 63,15 hat Gott selbst einen [מעה], wo das Gefühl Gottes, מֶֶעי (dein großes Mitleid), in diesem Körperteil verortet ist.

\section{Transzendentale Bedeutungen}

Die Gottesbeziehung ist eng mit dem Mutterschoß, wie auch mit den Brüsten, die den nächsten Schritt nach dem Mutterschoß (Grohmann 2007:140) darstellen, in Pss 22,10 und 131 verbunden. Gott wird also im Körper erfahren. Die bildspendenden Körperteile, der Mutterschoß und die Brüste, und ihre Funktionen haben auch bildempfangende, transzendentale Verbindungen.

Alle Vorkommen des werden in dieser Verbindung verwendet. Dies könnte daher darauf anspielen, dass die Gebärmutter funktional auf Nachkommenschaft zielt unter dem Zeichen des Segens in 7,$13 ; 28,4.11 ; 30.9$, aber auch unter dem Zeichen der Verfluchung in 28,18.53. In 7,13

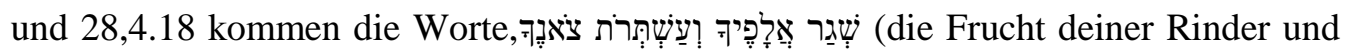
die Frucht deiner Schafe), vor, wo die ersten Nomina der jeweiligen Fügungen eigentlich Eigennamen sind, die hier schon als „Zuwachs“ verstanden werden: es handelt sich um die nordsyrische Schagar und die kanaanäische Fruchtbarkeitsgöttin Astarte (Keel \& Uehlinger 1998:166), die vielleicht beide als Mutterfiguren mit dem Mutterschoß verbunden waren.

Mit רֶֶ ist es anders: Auch die Natur (oder JHWH selbst) kann einen (metaphorischen) Mutterschoß haben: Obwohl das Meer als die (Große) verschlingende Mutter (Neumann 2004:188), die gebiert, und zugleich als überflutendes Unbewusstes alles bedroht (Neumann 2004:52), angesehen werden 
kann, ist es in Ijob 38,8 das Meer, das aus der Tiefe der Erde geboren wurde. Hier liest man auch von „Türen“ und diese Bilder gehen vielleicht unbewusst auf das

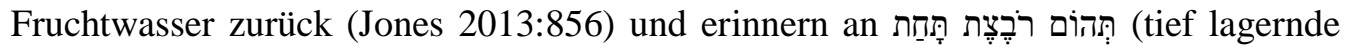
Urflut) in Gen 49,25. In Ijob 38,29 wird das Wort בָָּ auch für den Mutterschoß Gottes oder einen „kosmischen“ Bauch gebraucht.

Obwohl Grohmann (2007:43-44) die Erde als einen mythischen Restbestand ansieht, geht es bei der „Tiefe der Erde“ wahrscheinlich eher um die Verborgenheit und das Geheimnis als um die Erde als die Mutter und die Fruchtbarkeit, wie sie in der damaligen Zeit galt. Batmartha (1996:53) sieht auch die Parallele der Fruchtbarkeit

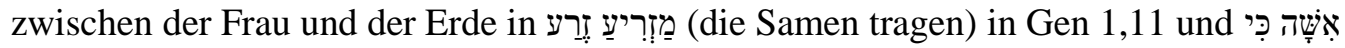
תַזְריעַ (wenn eine Frau niederkommt) in Lev 12,2.

Grohmann (2007:82) versteht die Erde als mögliche Gebärmutter in Pss 90,2, 97,4-5 und 114,7, obwohl sie sie (2007:91) eher als Bildsprache für Gott selbst ansieht. Auch in dem griechischen, spätisraelitischen 4 Esra 5,48 wird die Erde als Mutterschoß vorgestellt. Das bedeutet, dass die Erde wie eine Gebärmutter Gottes und der Kosmos als sein Körper symbolisiert werden, da sie seine Dauer und seine Beständigkeit ausdrücken. Die Geburtsmetaphern (in Gottes Rede nie das Bild des männlichen Zeugens [Fischer 1998:249]) sollten dann die enge persönliche Beziehung zwischen dem Schöpfer und der Schöpfung darstellen, die schon im Mutterleib besteht (vgl. Pss 22,10-11; 71,6; Jes 44,24).

In Ijob 1,21 wird die Erde auch in Verbindung mit dem Mutterschoß genannt, aber da handelt es sich um das Grab, den Tod, wo es auch Verborgenheit gibt (vgl. auch Prov 30,16). עָצְצִ (Mein Gebein) in Ps 139,15 hat auch die Konnotation des Todes. Beide, der Fötus und der Mutterschoß, sind wie Gott auch verborgen und haben darum etwas Göttliches an sich. Diese Verborgenheit schafft hier eine Atmosphäre der Wehrlosigkeit und Intimität (Grohmann 2007:43). Ps 139,13-16 geht unter den Psalmen, laut Grohmann (2007:312), ,am ausführlichsten auf das vorgeburtliche Leben" ein.

Die Verbindung mit der Erde verleiht dem Mutterschoß eine kosmologische Bedeutung: die Vorstellung von der Schöpfung des Menschen aus und in der Tiefe der 
Erde vergleicht den Mutterschoß mit der Erde (Häusl 2010:144-145). Der weibliche Körper kann als Himmelskörper angesehen werden: Ihr Mutterschoß gleicht der tiefen Erde in Ps 139,15 und ihre Brüste dem Himmel, wie in Gen 49,25, wo der Segen des

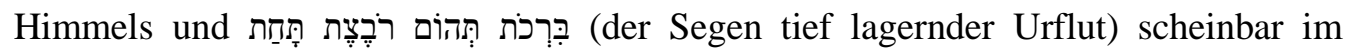

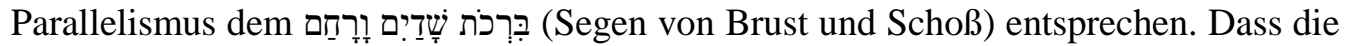
Mutterbrüste einem Kleinkind als bewundernswerte „Sterne“ aussehen können, wenn es nach oben blickt, ist leicht vorstellbar. (Auch in Hos 9,14 wird der Mutterschoß zusammen mit den Brüsten genannt, da aber als bestrafte Körperteile.) In Ugarit hieß Athirat, eine Meeresgöttin, auch Raḥmay (Mutterschoß), wie hier in Gen 49,25 (Keel \& Uehlinger 1998:82).

Diese Gefühlshaltung des Göttlichen haben laut Jüngling (1991:84) vor allem Geburtsgöttinnen, die oft auch Schicksalsgöttinnen sind, wie die ägyptische Meschenet (Strack 2014:51). Nicht nur wird der sumerische Mondgott Nanna als „Mutterschoß, der alles gebiert“ angesprochen, sondern auch andere Gottheiten, wie die ägyptischen Götter Amun-Re und Osiris, haben mütterliche und väterliche Eigenschaften (Jüngling 1991:93-95). Gott wird darum auch durch Körperbilder symbolisiert. Das erinnert daran, dass alle Symbolisierung vom Körper abgeleitet wird (Gliserman 1996:3) und die Begriffsbestimmung von Geertz, die besagt, dass die Religion ein Symbolisierungssystem ist, das verschiedene Stimmungen schafft (Kunin 2003:153).

רֶֶֶ wird in Ijob 38,8 als Ursprung des Meeres übertragen und in Ps 110,3 (wenn der Text korrekt ist) wird es für die Morgendämmerung, die den Tau gebiert, als Ausdruck der Hoffnung gebraucht. Hinter diesen Texten stehen mythische Vorstellungen des Numinosen. und verweist im Alten Orient im Allgemeinen auf eine Göttin, die die Sonne als ihren Sohn gebiert. Sie ist Belet-ili im Atramhasis-Mythos und im Sumerischen stellen $\mathrm{SIG}_{7}$-en und $\mathrm{SIG}_{7}$-Šar vielleicht personifizierte Eierstöcke dar (Grohmann 2007:105). Obwohl die Berge in Ps 90,2 selbst geboren werden, kann in Ps 110,3 der Horizont (d.h. die Horizontberge) auch als Mutterschoß der Morgenröte verstanden werden, v.a.

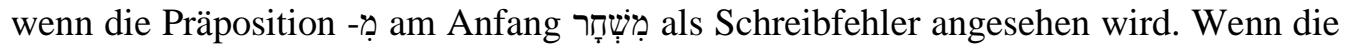


Präposition richtig ist, kann man auch zwei parallele Zeitangaben ohne eine Genitivverbindung und ohne Personifizierung der Morgenröte annehmen (Grohmann 2007:112), die dann eine Metapher des Lebensanfangs ist (Grohmann 2007:97). Wenn

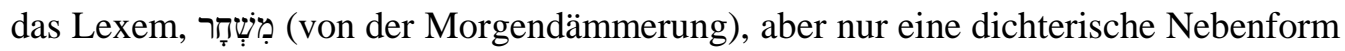
zu מָרֶֶֶם (vom Mutterschoß) ist, bekommt der Mutterleib hier eine göttliche Konnotation.

Der Mutterschoß ist der Ort des Wunders, gar der (Gegen-) Schöpfung (z.B. in Ijob 38) und ist eng mit Gott als Subjekt verbunden ${ }^{11}$. Auch in Ps 2,7; 90,2 und Dtn32,18 ist Gott der Gebärer bzw. die Gebärerin. Obwohl Grohmann (2007:37) glaubt, dass beide Gott und die Frau in „Koproduktion“ sind, wird die Frau nirgendwo genannt. Man muss nicht so weit gehen wie Coetzee (Grohmann 2007:32n30) und annehmen, die Frau sei absichtlich verneint, sie bleibt aber im Hintergrund. Obwohl

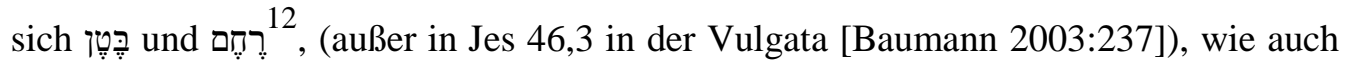
andere geschlechtliche Körperteile (Baumann 2003:242) in der Hebräischen Bibel nie auf Gott beziehen, finden sich [מעה] (dreimal aus insgesamt 30mal in der Hebräischen Bרִ קרב (nur einmal aus insgesamt 227mal in der Hebräischen Bibel) wohl so benutzt.

Weil sich das Pluraletantum, רַחִמִִִים (Mitleid, Erbarmen, „Mutterschößigkeit“ [Strack 2014:100]) von רִ am häufigsten auf Gott bezieht, bringt dieser Gebrauch göttliche Assoziationen des Mutterleibes hervor. Diese Beschreibung Gottes kommt viel im Islam vor: Zwei semantisch verwandte Wörter werden auch am Anfang fast jeder Sure (außer der Neunten) und auch in Sure 27,30 im Koran Allah zugeschrieben: بسم الله الرحمن الرحيم (bismi 'llāhi 'r-raḥmāni 'r-raḥimi: Im Namen des barmherzigen und gnädigen Gottes).

Der Mutterschoß ist nicht nur eine Bestimmungszuweisung, er hat auch beschützende Funktionen. Schroer (1997:298-299) verbindet Jes 49,1, wo Gott schon

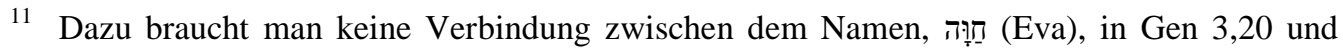
dem Tetragramm (Ulrich 1998:158), oder zwischen dem Namen, קִי (Kain), in Gen 4,1 und das Verb, קנגה (Schöpfer) in Gen 14,19 (Ulrich 1998:161) zu sehen.

12 Baumann (2003:246) übersetzt aber רַחְמִים neben ,Erbarmen“ auch als ,Eingeweide“, (die diese Emotion beheimatet), und findet das Wort 39mal in der Hebräischen Bibel, 25mal auf Gott bezogen. 
in der Gebärmutter die Berufung ausspricht und den Namen seines Knechtes gibt, mit Jes 51,16, wo mit den gleichen Worten der Berufene unter dem Schutz des „Schattens“ der „Hand“ Gottes versorgt wird. In dieser Metaphorik erkennt Schroer die Flügel Gottes, wie sie in den Psalmen, Ex 19,4, Dtn 32,11 und Mal 3,20 genannt werden und die von Schroer mit den ägyptischen geflügelten Göttinnen, wie Isis (oder Uto), Nephtys (oder Nechbet) und Maat, die als Ideogramm für Mutterschaft, Gebärmutter und Sarg verwendet wird, verglichen werden. Schroer (1995a:70) weist auch auf die Bedeutung von רָזָדָמָה (beide eine Geierart) in Dtn 14,17 hin. In Ex 19,4 und Dtn 32,11 wird Gott als (vielleicht Gänse-) Geier dargestellt, eine wohlbekannte Göttin in Ägypten und Vorderasien bis in den südarabischen Raum (obwohl dieser häufig erwähnte wild lebende Vogel in der Hebräischen Bibel als unrein betrachtet wird, vermutlich, weil der Geier, wie die Große Mutter [Neumann 2004:57ff und 236f], nicht nur mit der Geburt, sondern als Aasfresser auch mit dem Tod verknüpft ist). Die geflügelten Göttinnen stillen den König, aber bewachen auch seine Leiche.

Weil Gott nie mit den Keruben, die auch als geflügelt vorgestellt werden, identifiziert wird und der Mensch nie Schutz unter deren Flügeln sucht, scheint es, dass Gott selbst die geflügelte Sonne- oder Himmelsscheibe ist, die von den bezüglichen Psalmen (z.B. 17,7f; 57, 2; 61, 4f; 63, 8f) widerspiegelt wird.

Hinter Mal 3,20 und Ps 110,3b steht wahrscheinlich das ägyptische Grabbild der Sonne als Kälbchen zwischen zwei Sykomoren, geboren von der Himmelskuh, der Morgenröte als Göttin Nut (Schroer 1997:306-307). Wenn dies der Fall ist, symbolisieren die Flügel also ursprünglich den Mutterschoß. Durch den patriarchal geprägten Monotheismus wurde dieser weibliche Körperteil jedoch verdrängt und ist in der männlichen Gottheit ohne Kennzeichnung des weiblichen Ursprungs integriert worden.

Dass das Grab auch als der Mutterschoß der Erde angesehen wurde, ist klar aus den vielen, omega-ähnlichen, reliefierten Gefäßen, in denen der Kopf des Verstorbenen geborgen wurde (Schroer 1995b:170; vgl. auch Balogh 2012:164). Dieses Symbol bezieht sich auf die altbabylonischen Muttergöttinnen, wie 
Ninhursanga oder Nintu, die als „Gebärmutter“ angesprochen wurden (Strack 2014:51), und begegnen uns in Juda bis in der Eisenzeit II C (700-600 v.u.Z.) mit vielleicht apotropäischer Wirkung. Dass der Mutterschoß zweideutig ist, wird weiter dadurch bekräftigt, dass auch lebende Kinder wahrscheinlich dieses Zeichen trugen

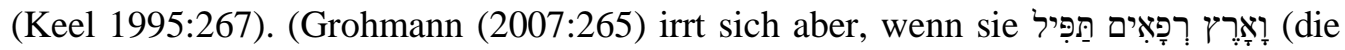
Erde gibt die Toten heraus) in Jes 26,19 nicht als Leben, sondern als das Gebären der „Totenschatten“ versteht, weil es hier um eine Art Auferstehung geht.) Der Mutterschoß funktioniert als Bezugspunkt, wie ein Denkmal, zu dem man sich in seiner erinnernden Regression, insbesondere während seiner Unreife oder während Krisen hinwenden kann. Im Ps 71 wird der Mutterschoß in Vers 6 kurz nach dem Fels als Gottesbild in Vers 3 verwendet. Beide sind wie Anker der Vergangenheit. Auch Ijob 1,21a; 3,10.11 und 10,19 (wie Gen 3,19 und Sir 40,41) verbinden den Mutterschoß mit der Erde und die Geburt mit dem Tod, wie auch Jer 20,17 und Num 12,12 (wo eine Frau, Mirjam, als eine Fehlgeburt und die Angst davor geschildert werden) den Mutterschoß mit dem Tod gleichsetzen und Hos 9,14 einen ähnlichen

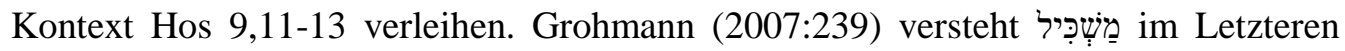
nicht nur als fehlgebärenden, sondern auch als unfruchtbaren Mutterschoß. Obwohl kein Mutterschoß in Hos 13,13 ausdrücklich genannt wird, geht es auch hier um die Gebärmutter als Grab: Das Kind weigert sich, geboren zu werden (Wacker 1998:309). (Grohmann (2007:311) hat nicht recht, dass es in Ps 58,4 allein um einen Vergleich zwischen den Frevlern und einer Fehlgeburt geht (das kommt erst in V. 9 vor.) Die Gefahr der Fehlgeburt konnte die Gebärmutter als eine Krisensituation zwischen Leben und Tod (Gies 2009:335) und Schwangerschaft und Geburt als Schwellensituationen und Gratwanderungen markieren (Häusl 2005:1-2). Implizit wird der Mutterschoß in Geburtsvergleichen mit Not und Todesgefahr verbunden (Häusl 2003:95, passim). Das findet sich z.B. auch metaphorisch in 2. Kőn 19,3 (= Jes

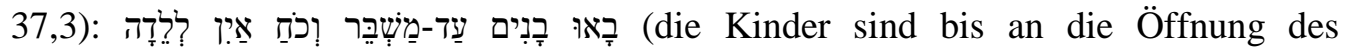
Mutterschoßes [d.h. den Muttermund] gelangt, doch den Frauen fehlt die Kraft zum Gebären), sagt König Hiskija, wenn eine Krise droht (vgl. auch Hos 13,13). Das Wort,

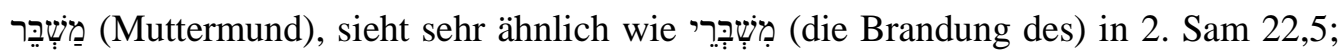


Jona 2,4; Pss 42,8; 88,8; 93,4 aus und verstärkt also die Verbindung mit durchbrechendem Fruchtwasser.

Das Wort, רֶֶֶּ, wim Theologische(n) Handwörterbuch zum Alten Testament (Jenni \& Westermann 1971:761-768) genannt, weil es sich angeblich nie auf Gott bezieht (Baumann 2003:236). Die Lexeme besitzen jedoch manchmal indirekte Hinweise auf das Jenseitige. In den Psalmen bedeutet (wahrscheinlich) in 31,10 (es ist nicht klar, wie Grohmann [2007:119] hier wie in 17,14 eine Klage über Kinderlosigkeit vermuten kann) und in 44,26 immer den Mutterschoß. In 22,10 und 139,13 steht es in Verbindung mit אִִ̣̣ (meiner Mutter) und in 127,3 und 132,11 mit פְּרִ (die Frucht). Obwohl das Letzte ein allgemeiner Ausdruck in der Hebräischen Bibel ist (Grohmann 2007:170), unterstellt es bildsprachlich den Mutterschoß als eine Pflanze, einen Baum, v.a. in Hos 9,16, wo auch שָׁרָשָׁ (seine Wurzeln) und (die geliebte Frucht) genannt werden. Das bestätigt wahrscheinlich eine archäologische Darstellung eines Baumes aus Bet-Schemesch, unter dem ein Gebirge gezeigt wird. Keel \& Uehlinger (1998:172-173) meint, dass diese „Unterwelt“،, in etwa die Toten in Gen 35,8 und 1. Sam 31,13 beerdigt werden, den Mutterschoß der Erde, in die die Verstorbenen zurückkehren, bezeichnet; er vermutet auch, dass die frühisraelitischen, heiligen Bäume bei Qadesch in Naftali, Sichem, Ofra, Mamre und Beerscheba die gleichen Bedeutungen hatten.

Trotz des liebevollen, mütterlichen Gottesbildes in Hos 11 (vgl. Wacker 1998:307308) wird der Mutterschoß Ephraims dreimal in Hos 9.14.16 ausdrücklich abgewertet, gar verflucht: man ,betet“ um Unfruchtbarkeit, Fehl- und Todgeburt und Tod nach der Geburt. Auch in Hos 12,4 hängt der Schatten über der Geschichte Israels schon im Mutterleib. Diese Tragödie mit dem Mutterschoß geht weiter, bis sie den Fall der Fälle

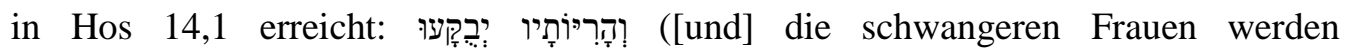
aufgeschlitzt). Erst nach diesen schrecklichen Bildern ist eine Umkehr Israels möglich.

Im alten Mesopotamien war die Unterwelt auch der Geburtsplatz (Balogh 2012:162). Das erinnert an Jona 2,3, wo der Prophet - kann man sagen, vor seiner

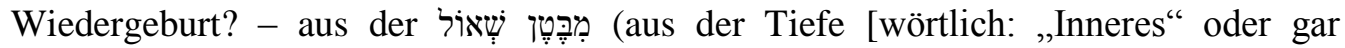
„Mutterschoß“] der Unterwelt) betet, und wie Ijob seine Erfahrungen auch vielleicht 


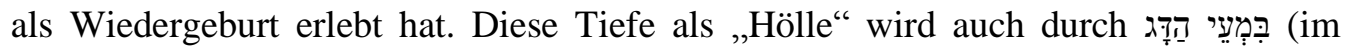
Bauch des Fisches oder „der Seeschlange“, das Ursymbol der Angst [Drewermann 1985:388]) am Ende der Welt in Jona 2,1.2 (im Letzteren mit der Präposition ִ̣) symbolisiert. Dazu kommt noch, dass die manchmal labyrinthförmigen Gräber ein Hinweis auf den Mutterschoß sind (Schmölzer 2005:9). Diese Gedanken, dass die dunkle Unterwelt auch ein Mutterschoß sein kann, begegnen auch in Ps 139,15; auch wenn in Vers 13 schon der Mutterleib genannt wurde. Dass diese Idee laut Freedman und Lundbom (1977:617) nur in Ijob vorkommt, ist daher nicht wahr. Die Nebeneinanderstellung des Lebens und des Todes in Verbindung mit dem Mutterschoß kann auch als Merismus funktionieren, um anzudeuten, wie einschließend der Mutterschoß ist (Häusl 2007:82). Der „Große“ Mutterschoß (als eine Anspielung auf die "Große Mutter") würde so beide Gegensätze enthalten (Neumann 2004:107). Klein (1995:199) versteht רֶֶם in Ijob 38,8 wegen der übermäßigen Gewalt des Lebens im Wasser als eng mit dem Tod verknüpft. Dieses Paradox - oder Oxymoron, wie Alter (1985:99) es benennt - findet man auch in Ijob

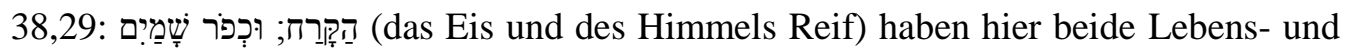
Todeskonnotationen. Auch קִּרכָּר (Grab) in einem Wortspiel verbunden. Weiterhin kann man in Ps 44,26 vermuten, dass לְָעָפָר (in den Staub) und לָאָָר (am Boden) an den Tod erinnern.

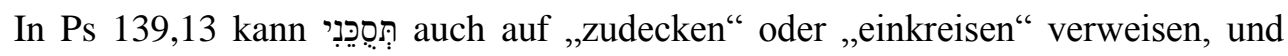
ruft deshalb Gott im Bild der Mutter hervor. Es ist auch möglich, dass das Verb die

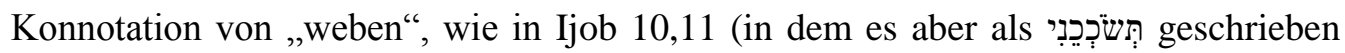
ist), haben kann, aber Balogh (2012:152-153) entscheidet sich für „ausgießen“ (der Samen des erzeugenden Gottes oder des Gottes als Bildhauers oder als Käser [vide infra]).

Eine Intimität besteht zwischen der Hebamme (Gott), dem neugeborenen Kind und der Mutter in Ps 22,10 (vgl. Trible 1993:54,77) und nach der Geburt zwischen Gott als Amme und dem Mensch, wie in Jes 44,2. Wenn Gott darüber hinaus auch als mütterlich und vielleicht auch mit einem Mutterschoß dargestellt wird, wird die Mutter vom Anfang bis zum Ende von einem weiblichen Gott begleitet, wie es in der 
vormodernen Zeit aussah (Schmölzer 2005 passim). In Ps 139,5 kann Gott sogar als Mutterschoß erkannt werden.

Sukzessive wurden Eigenschaften und daher auch Körperteile von Göttinnen in das männliche Gottesbild einbezogen und integriert, obwohl diese Entwicklung Frauenfeindlichkeit nicht ausschloss und zum Teil sogar begünstigte (Schroer 1995b:126).

Strack (2006:175) nennt drei Beispiele in der Bibel (alle drei aus der Hebräischen Bibel), wo der Frauenkörper „als Ort des Göttlichen“ zum Ausdruck kommt: In Gen 49,25 wird der Mutterschoß als Geschenk und als äußerster Segen betrachtet. Ähnlich einem Merismus steht er parallel zum Himmel und zur tief lagernden Urflut. Zweitens verweist sie auf die Verbindung der hebräischen Wörter für „Mutterschoß“ und „Erbarmen“ hin. Drittens verbindet sie רִּּ (Geist, Wind, Leben, Atem, usw.) in der Nachfolge der Alttestamentlerin Helen Schuengel-Straumann, mit Geburt als Zugang zur „Weite“, „Bewegung“ und zum „Raum“.

Während Strack über das eher unsichtbare, innere Frauenorgan und seinen Bezug zu Gott schreibt, beschreibt Wagner (2010:14) nur die äußere Gestalt (Außensicht) Gottes. Er ist sich aber bewusst, dass Anthropomorphismen, Anthropopathismen (von inneren Körperteilen abhängig) und Anthropopragmatismen (von äußeren Körperteilen abhängig) miteinander verzahnt sind. Äußere Körperteile sind eher auf Funktionen und Ausdrücke gerichtet, während sich innere Organe (eher) auf Erfahrungen (aber auch auf Funktionen), wie Gefühle, Gedanken und Eindrücke beziehen. Der Mutterschoß ist hierbei der Ort eines lebenswichtigen Geschehens.

\section{ZUSAMMENFÜHRUNG UND AUSBLICK}

Trotz der vielstimmigen „Erinnerungen“ als „Erfahrungen“ der Gebärmutter in der Hebräischen Bibel vertreten die obengenannten vier Bedeutungsebenen fast immer, wenn nicht immer, die/eine männliche Perspektive.

Die körperlichen Bedeutungen beziehen sich auf die idealisierte Frau und auf die Kinder von Menschen und Tieren. Ihre psychosomatischen Dimensionen führen 
weiter zu den psychologischen Bedeutungen, die Gefühle von Intimität, aber auch von Angst und männlichem Neid auslösen. Auf dieser Ebene werden die Doppeldeutigkeit und -wertigkeit, mit denen der Mutterschoß als archetypisches Bild verbunden ist, deutlich.

Diese komplexe und konfliktreiche Vielschichtigkeit drückt sich in den sozialen Bedeutungen aus, in denen eine patriarchale Haltung die Frau auf ein einziges Organ reduziert und den Mutterschoß als Ursprung unerwünschter Brüder und Frevler erklärt. Als Projektionsfläche wird der Mutterschoß als Ort der gesellschaftlichen, oft traditionell von Frauen ausgeübten Berufen geschildert. Hier findet man auch architektonische Beschreibungen, um die Geborgenheit und gesellschaftliche Verantwortung des Mutterschoßes zu widerspiegeln.

Die vierte Bedeutungsschicht, die der Transzendenten, beinhaltet die vielfache Polysemie. Hier handelt es sich um vorgeburtliche Berufungen, Gottes Segen bzw. Verfluchung, mythische Anspielungen auf numinöse Figuren, die Natur oder sogar den Tod als Mutterschoß. Letztendlich geht es hier implizit um Gott als gebärende und erbarmende Mutter, Hebamme und Amme, die das menschliche Leben aus dem Mutterschoß bis zum Grab als endgültige Gebärmutter begleitet. So wird der Mutterschoß das Symbol, mit dem man um seinen Lebenssinn ringt, aber aus dem man auch seine Bestimmung wahrnimmt.

Es ist deshalb klar, dass die vier verschiedenen Worte in der Hebräischen Bibel in ihren unterschiedlichen Zusammenhängen einen Reichtum und eine Fülle der realen menschlichen Auseinandersetzung mit der Gebärmutter darstellen.

\section{BIBLIOGRAFIE}

Alter, R 1985. The art of biblical poetry. New York: Basic Books.

Batmartha (Petermann), I J 1996. Machen Geburt und Monatsblutung die Frau ,unrein“? Zur Revisionsbedürftigkeit eines mißverstandenen Diktums, in Schottroff \&Wacker1996:43-60.

Bauer, A 1998. Das Buch Jeremia: wenn kluge Klagefrauen und prophetische Pornografie den Weg ins Exil weisen, in Schottroff \& Wacker 1998:258-269.

Baumann, G. Das göttlichen Geschlecht. JHWHs Körper und die Gender-Frage, in HedwigJahnow-Forschungsprojekt 2003:220-250.

Balogh, C 2012. Schöpfung und Geburt: anthropologische Begrifflichkeit in Psalm 139, 13-16, 
in Sacra Scripta, X / 2:147-176.

Beer, B 2002. Körperkonzepte, interethnische Beziehungen, Rassismustheorien: eine kulturvergleichende Untersuchung. Berlin: Dietrich Reimer.

Botterweck G J \& Ringgren H 1977. Theologisches Wörterbuch zum Alten Testament. Band I.

Stuttgart: W. Kohlhammer.

Botterweck G J \& Ringgren H 1990. Theologisches Wörterbuch zum Alten Testaments. Band 7.

Stuttgart: W. Kohlhammer.

Brenner, A 1995. Feminist companion to wisdom literature. Sheffield: Academic Press.

Dahmen, U \& Simian-Yofre, H. רחם rhm,in Botterweck \& Ringgren 1990:460-477.

Die Bibel: Lutherübersetzung mit Apokryphen, 1984. Deutschen Bibelgesellschaft.

Dieckmann D \& Erbele-Küster D, 2006.,,Du hast mich aus meiner Mutter Leib gezogen “.

Beiträge zur Geburt im Alten Testament (Biblisch-Theologische Studien). Neukirchen-

Vluyn: Neukirchener.

Drewermann, E 1985. Tiefenpsychologie und Exegese: die Wahrheit der Werke und der Worte:

Wunder, Vision, Weissagung, Apokalypse, Geschichte, Gleichnis. Band II. Olten: Walter.

Ferenczi, S 1924. Versuch einer Genitaltheorie. Wien: Internationaler Psychoanalytiker Verlag.

Fischer, I 1998. Das Buch Jesaja: das Buch der weiblichen Metaphern, in Schottroff \& Wacker1998:246-257.

Freedman D N. \& Lundbom J R. ำ in Botterweck \& Ringgren1977:616-619.

Freud, S [1917] 1929. Introductory lectures on psycho-analysis. London: George Allen \& Unwin .

Freud, S [1900] 1986. The interpretation of dreams. London: George Allen \& Unwin.

Frevel C 2010. Biblische anthropologie: neue Einsichten aus dem Alten Testament. Freiburg: Herder.

Gies, K 2009. Geburt: ein Übergang: rituelle Vollzüge, Rollenträger und Geschlechterverhältnisse: eine alttestamentliche Textstudie. Arbeiten zu Text und Sprache in der Hebräischen Bibel. 88. Band. St. Ottilien, EOS.

Gliserman, M J 1996. Psychoanalysis, language and the body of the text. Gainesville: University Press of Florida.

Grohmann, M 2006. ,Du hast mich aus meiner Mutter Leib gezogen“: Geburt in Ps 22, in Dieckmann \& Erbele-Küster 2006:73-97.

Grohmann, M 2007. Fruchtbarkeit und Geburt in den Psalmen. (Forschungen zum Alten Testament 53). Tübingen: Mohr Siebeck.

Häusl, M 2002. Ps 17 - Bittgebet einer kinderlosen Frau?, in Irsingler 2002:205-222.

Häusl, M 2003. Bilder der Not: Weiblichkeits- und Geschlechtermetaphorik im Buch Jeremia. Herders Biblischen Studien, Band 37. Freiburg: Herder.

Häusl, M 2005. Geburt - Kampf um Leben und gegen den Tod: alttestamentliche Vorstellungen und Rituale für Mutter und Kind am Anfang des Lebens, in Heininger 2005:202-254.

Häusl, M 2007. Die Zeit der Schwangerschaft, in Steingrímsson \& Olason 2007:69-85.

Häusl, M 2010. Auf den Leib geschrieben: Körperbilder und -konzepte in der Hebräischen Bibel, in Frevel 2010:134-163.

Hedwig-Jahnow-Forschungsprojekt, 2003. Körperkonzepte im Ersten Testament. Aspekte einer feministischen Anthropologie.Stuttgart: W. Kohlhammer.

Heininger B 2005. An den Schwellen des Lebens - geschlechtsspezifische Aspekte von Übergangsriten, Geschlecht-Symbol-Religion 3.Münster: Lit. 
Irsingler H 2002. Wer darf hinaufsteigen zum Berg JHWHs? Beiträge zu Prophetie und Poesie des Alten Testaments. Festschrift für Sigurdur Örn Steingrímsson zum 70. Geburtstag. St. Ottilien: EOS.

Jenni, E \& Westermann, C 1971. Theologisches Handwörterbuch zum Alten Testament. Band I. München: Christian Kaiser.

Jenni, E \& Westermann, C 1976. Theologisches Handwörterbuch zum Alten Testament. Band II. München: Christian Kaiser.

Jones, S C 2013. Corporeal discourse in the book of Job, in Journal of Biblical Literature, 132/4:845-863.

Jung, C G 1984. Dream analysis: Notes of the seminar given in 1928-1930. Princeton: University Press.

Jost, R \& Seifert, E 1998. Das Buch Ezekiel: Männerprophetie mit weiblichen Bildern, 278290 in Schottroff \& Wacke 1998:27.

Jüngling, H-W 1991. Bemerkungen zur Wechselwirkung zwischen den Auffassungen von der Frau und der Darstellung von Göttinnen, in Wacker \& Zengler1991:82-105.

Kassel, M 1987. Biblische Urbilder: tiefenpsychologische Auslegung nach C. G. Jung. München: J. Pfeiffer.

Keel, O 1984. Deine Blicke sind Taube:.zur Metaphorik des Hohenliedes. (SBS 114 / 115). Stuttgart: Verlag Katholisches Bibelwerk.

Keel, O 1995. Corpus der Stempelsiegel-Amulette aus Palästina, Israel: von den Anfängen bis zur Perserzeit. Freiburg, Schweiz: Universitätsverlag.

Keel, O \& Uehlinger, C 1998. Göttinnen, Götter und Gottessymbole: neue Erkenntnisse zur Religionsgeschichte Kanaans und Israels aufgrund bislang unerschlossener ikonographischer Quellen. (4. erweiterte Auflage). Freiburg: Herder.

Kessler, R, Ulrich,U, Schwantes, M \& Stansell, G 1997. „Ihr Völker alle, klatscht in die Hände! “. Festschrift für Erhard S. Gerstenberger zum 65. Geburtstag: Exegese in unserer Zeit. Kontextuelle Bibelinterpretationen, Band 3. Münster: Lit.

Kiesow, A 2003. Auf der Suche nach dem Menschen, in Hedwig-Jahnow-Forschungsprojekt 2003:29-41.

Klein, L R 1995. Job and the womb: Text about men; subtext about women, in Brenner1995:186-200.

Klinger,E Böhm, S \& Seidl, Th 2000. Der Körper und die Religion: das Problem der Konstruktion von Geschlechterrollen. Würzburg: Echter.

Krieg, M 1983. Leiblichkeit im Alten Testament,in Krieg \& Weder 1983:7-29.

Krieg M \& Weder, H 1983. Leiblichkeit. Zürich: Theologischer Verlag.

Kronholm, T 1990. רֶֶ ræhœm,477-482 in Botterweck \& Ringgren1990:477-482.

Kunin, S D 2003. Religion: the modern theories. Edinburgh: University Press.

Maier, C \& Schroer, S 1998. Das Buch Ijob: Anfragen an das Buch vom leidenden Gerechten, in Schottroff \& Wacker 1998:192-207.

Neue Echter Bibel: Kommentar zum Alten Testament mit der Einheitsübersetzung 1980.

Stuttgart: Katholisches Bibelwerk.

Neumann, E 2004. Ursprungsgeschichte des Bewusstseins. Zürich: Walter.

Rank, O [1923] 1988. Das Trauma der Geburt und seine Bedeutung für die Psychoanalyse. Frankfurt/M: S. Fischer.

Schmölzer, H 2005. Die abgeschaffte Mutter: der männliche Gebärneid und seine Folgen. Wien: Promedia.

Schottroff, L, Schroer, S \& Wacker, M-Th 1995. Feministische Exegese: Forschungserträge zur Bibel aus der Perspektive von Frauen. Darmstadt: Wissenschaftliche 
Buchgesellschaft.

Schottroff L \& Wacker M-Th, 1996. Von der Wurzel getragen: christlich-feministische Exegese in Auseinandersetzung mit Antijudaismus. Leiden: Brill.

Schottroff, L \& Wacker, M-Th 1998. Kompendium: feministische Bibelauslegung. Gütersloh: Christian Kaiser / Gütersloher Verlagshaus.

Schroer, S 1995a. Die Göttin und der Geier, in Zeitschrift des deutschen Palästina-Vereins 111: 60-80.

Schroer, S 1995b. Die Gebärmutter und das Mitgefühl, in Schottroff, Schroer \& Wacker 1995:169-172.

Schroer, S 1997. 'Im Schatten deiner Flügel': religionsgeschichtliche und feministische Blicke auf die Metaphorik der Flügel Gottes in den Psalmen, in Ex 19,4; Dtn 32,11 und in Mal 3,20, in Kessler, Ulrich, Schwantes \& Stansell 1997: 296-316.

Schroer, S \& Staubli, Th 2005. Die Körpersymbolik der Bibel. Gütersloh: Gütersloher Verlagshaus.

Seidl, Th 2000. 'Schön bist du meine Freundin': Wahrnehmung des Körpers im Hohenlied, in Klinger, Böhm \& Seidl 2000:129-158.

Sloterdijk, P 2000. Sphären: Band 1: Mikrosphärologie: Blasen. Frankfurt / M: Suhrkamp.

Steingrímsson S O \& Olason K 2007. Literatur- und sprachwissenschaftliche Beiträge zu alttestamentlichen Texten. Symposion in Hólar i Hjltadal, 16.-19. Mai 2005. Wolfgang Richter zum 80. Geburtstag. ATS 83, St. Ottilien: EOS.

Stoebe, H J 1976. רחם rhm pi. Sich erbarmen, in Jenni \& Westermann1976:762-767.

Strack, H 2006. Die Frau ist Mit-Schöpferin: eine Theologie der Geburt. Rüsselsheim: Christel Göttert.

Strack, H 2014. Spirituelle Reise zur Gebärmutter: entdecken, staunen, würdigen. Münster: ATE.

Trible, P 1993. Gott und Sexualität in der Hebräischen Bibel. Gütersloh, Gerd Mohn.

Van der Zwan, P 2014. Song of Songs: from transcending to 'transcendental' sex (1), in Journal for Semitics 23/2ii: 841-860.

Wacker, M-Th 1998. Das Buch Hosea: der gott-identifizierte Mann und die Frau(en) Israel(s) in Schottroff \& Wacker1998: 299-311.

Wacker M-Th \& Zengler E 1991. Der eine Gott und die Göttin: Gottesvorstellungen des biblischen Israel im Horizont feministischer Theologie. Freiburg: Herder.

Wagner, A 2010. Gottes Körper: zur alttestamentlichen Vorstellung der Menschengestaltigkeit Gottes. Gütersloh: Verlagshaus.

Wolff, H W [1973] 2002. Anthropologie des Alten Testaments (KT 91). Gütersloh: Christian Kaiser. 